\title{
ORIGINAL
}

\section{Interleukin-18 induces insulin resistance in the hyperthyroid state}

\author{
Shozo Miyauchi ${ }^{1)}$, Bunzo Matsuura ${ }^{2)}$, Teruhisa $\mathrm{Ueda}^{3)}$, Tohru Eguchi ${ }^{1)}$, Masaaki Tamaru ${ }^{4)}$, Shin Yamamoto ${ }^{3)}$, \\ Teruki Miyake ${ }^{3)}$, Shinya Furukawa ${ }^{3)}$, Masanori $\mathrm{Abe}^{3)}$, Yoichi Hiasa ${ }^{3)}$ and Morikazu Onji ${ }^{3)}$ \\ 1) Department of Internal Medicine, Uwajima City Hospital, Uwajima 798-8510, Japan \\ 2) Department of Lifestyle-related Medicine, Ehime University Graduate School of Medicine, Toon 791-0295, Japan \\ 3) Department of Gastroenterology and Metabology, Ehime University Graduate School of Medicine, Toon 791-0295, Japan \\ 4) Department of Internal Medicine, Saiseikai Imabari Hospital, Imabari 799-1592, Japan
}

\begin{abstract}
We previously reported that serum interleukin-18 (IL-18) levels were significantly increased in hyperthyroid Graves' disease patients. The development of insulin resistance in hyperthyroidism has been documented. We investigated the relationship between IL-18 and insulin resistance in patients with hyperthyroid Graves' disease and in experimental hyperthyroid mice. Then, we examined whether IL-18 induces insulin resistance in mice injected with IL-18 for a week. A significant positive correlation was observed between serum IL-18 levels and parameters such as thyroid functions and homeostasis model assessment for insulin resistance in hyperthyroid Graves' disease. In experimental hyperthyroid mice, IL-18 was significantly elevated. Insulin resistance increased in experimental hyperthyroid mice and IL-18-injected mice. These findings suggest IL-18 to be an important factor inducing insulin resistance in hyperthyroidism.
\end{abstract}

Key words: Graves' disease, Hyperthyroidism, Interleukin-18, Insulin resistance, HOMA-R

HYPERTHYROIDISM is associated with significant aberrations of carbohydrate, lipid and protein metabolism. An increased incidence of glucose intolerance, usually of mild-to-moderate severity, is documented in $30-50 \%$ of patients with hyperthyroidism [1]. Carbohydrate metabolism is characterized by increased oxygen consumption, rapid gastric emptying, enhanced gluconeogenesis and glycogenolysis. Many of these effects are reproducible in experimental hyperthyroidism induced in non-diabetic [2] and diabetic individuals [3]. The insulin clearance rate was found to be increased by approximately $40 \%$ in hyperthyroid states [4]. The data on peripheral glucose disposal and insulin sensitivity are controversial. One study noted decreased peripheral insulin sensitivity [5], whereas most others found it to be normal [4] or increased $[2,6]$ as compared with that in controls, primarily because of enhanced rates of glucose oxidation as determined by

Submitted Apr. 8, 2012; Accepted Nov. 21, 2012 as EJ12-0136

Released online in J-STAGE as advance publication Dec. 19, 2012

Correspondence to: Shozo Miyauchi, M.D., Department of Internal Medicine, Uwajima City Hospital, Uwajima, Ehime 798-8510, Japan.Email: syozo@uwajima-mh.jp indirect calorimetry.

Interleukin-18 (IL-18), also known as interferon- $\gamma$ inducing factor, is a pleiotropic cytokine like IL-12 [7]. We previously reported that serum IL-18 levels in Graves' disease were significantly increased in the hyperthyroid state and then decreased during treatment with methimazole (MMI) or propylthiouracil (PTU) [8].

IL-18 is also reportedly related to insulin resistance in subjects with obesity and/or the metabolic syndrome [9]. Furthermore, IL-18 mediates insulin resistance with other cytokines such as IL- $1 \beta$ and TNF- $\alpha$. However, there are few reports on the relationship between IL-18 and insulin resistance in thyrotoxicosis.

We investigated whether IL-18 is involved in the increased insulin resistance characteristic of hyperthyroidism.

\section{Subjects and Methods}

\section{Subjects}

We studied 10 patients with Graves' disease (1 male and 9 females; mean age $39.3 \pm 14.6$ years, range 14-64 years, median 38 year). None had a diagnosis of dia- 
betes mellitus or metabolic syndrome. Graves' disease had been diagnosed by clinical features such as diffusely enlarged thyroid glands, exophthalmos, tachycardia, tremor and sweating and laboratory data such as undetectable serum thyrotropin (TSH) and elevated serum free tri-iodothyronine (fT3), free thyroxine (fT4) and TSH receptor antibody (TRAb), as well as by measuring thyroidal uptake of $99 \mathrm{mTc}$ and imaging of the $99 \mathrm{mTc}$ distribution pattern in the thyroid.

Serum TSH, fT3, fT4, and TRAb levels were measured by using the Elecsys ECLIA kit (Roche Diagnostics, Tokyo, Japan). Briefly, mean levels of TSH, fT3, fT4 and TRAb in Graves' disease were less than $0.01 \mu \mathrm{IU} / \mathrm{mL}, 19.1 \pm 10.1 \mathrm{pg} / \mathrm{mL}, 5.0 \pm 2.6 \mathrm{ng} / \mathrm{dL}$ and $21.1 \pm 13.6 \mathrm{IU} / \mathrm{L}$, respectively, in the hyperthyroid state. All patients were medicated with MMI and then became euthyroid.

Homeostasis model assessment for insulin resistance (HOMA-R) was calculated from levels of fasting plasma glucose (FPG) and fasting immunoreactive insulin (FIRI) as follows: (FPG $(\mathrm{mg} / \mathrm{dL}) \times$ FIRI $(\mu \mathrm{U} /$ $\mathrm{mL}$ )/405). Homeostasis model assessment beta cell (HOMA- $\beta$ ) was calculated as follows: (FIRI $[\mu \mathrm{U} / \mathrm{mL}$ ] $\times 360 /(\mathrm{FPG}[\mathrm{mg} / \mathrm{dL}]-63)[10,11]$. Briefly, the mean levels of FPG, FIRI, HOMA-R and HOMA- $\beta$ were $99.7 \pm 9.5 \mathrm{mg} / \mathrm{dL}, 9.4 \pm 5.3 \mu \mathrm{IU} / \mathrm{mL}, 2.3 \pm 1.4$ and 93.8 $\pm 44.9 \%$, respectively, in the hyperthyroid state.

The serum parameters were measured employing samples obtained from fasting patients at the time Graves' disease was diagnosed, and at 1, 3 and 6 months after diagnosis.

All subjects provided informed consent prior to enrollment in this study.

\section{Materials}

L-thyroxine (T4) was purchased from Wako Pure Chemical Industries Ltd, Tokyo, Japan. Recombinant mouse IL-18, mouse IL-18 kits and human IL-18 ELISA kits were from MBL (Woburn, MA, USA).

\section{Treatment of mice}

Male C57BL/6 mice obtained from Clea Japan Inc. (Tokyo, Japan) were housed, 5 per cage, under controlled temperature and illumination. Food and water were freely available. All mice received humane care in compliance with our Institution's guidelines. A hyperthyroid state was induced in the 8-week-old mice by administering drinking water mixed with $2 \mathrm{mg} / \mathrm{mL}$ L-thyroxine (T4) for 4 weeks [12]. We estimated the total amount of T4 administered per mouse to be 10 $\mu \mathrm{g} /$ day. The mice were divided into two groups: thyroid control $(\mathrm{C})$ and $\mathrm{T} 4$ treated $(\mathrm{T})$. In the $\mathrm{T}$ group, the weight of the mice increased from $22.0 \pm 0.5 \mathrm{~g}$ to 24.6 $\pm 0.6 \mathrm{~g}$, and in the $\mathrm{C}$ group, it increased from $20.2 \pm 0.7$ $\mathrm{g}$ to $22.8 \pm 0.3 \mathrm{~g}$; there were no significant differences in the weight changes between the 2 groups.

Eight-week-old mice were injected with mouse IL-18 (200 ng/mouse) intraperitoneally on alternate days for one week. The mice were then divided into two groups: vehicle control and IL-18 treated. At various intervals, approximately $100 \mu \mathrm{L}$ of blood were obtained from the tail vein. After overnight fasting, intraperitoneal glucose tolerance tests (IPGTT) (glucose $1.0 \mathrm{mg} / \mathrm{g}$ body weight) were performed after 4 weeks of treatment with T4 and 1 week of treatment with IL-18 [13].

Sera were separated by centrifugation and stored at $-20^{\circ} \mathrm{C}$ until analyses using the same assay for each point. Plasma glucose (PG) levels were measured using a glucosensor (Glucose Pilot; Syntron Bioresearch, Carlsbad, CA, USA). Serum insulin (IRI) levels were assayed using a mouse insulin ELISA kit (Morinaga Institute of Biological Science, Yokohama, Japan). The areas under the curve for plasma glucose (PG-AUC) and insulin (IRI-AUC) were calculated using the trapezoidal rule.

\section{Assay of IL-18}

Human serum IL-18 levels were assayed using a human IL-18 ELISA kit (MBL) according to the manufacturer's protocol.

\section{Statistical analysis}

Data were expressed as means $\pm 1 \mathrm{SD}$. The data were statistically analyzed using unpaired $t$-tests and nonparametric Mann-Whitney rank-sum tests. A value of $P<0.05$ was considered to indicate a statistically significant difference.

\section{Results}

\section{Serial changes in HOMA-R in Graves' disease}

At the time of diagnosis of Graves' disease, the mean HOMA-R in the study patients was $2.3 \pm 1.4$; this value decreased significantly during treatment with anti-thyroid drugs ( 1 month, $2.1 \pm 1.2 ; 3$ months, $1.77 \pm 0.9 ; 6$ months, $1.13 \pm 0.4$; Fig. 1$)$. 


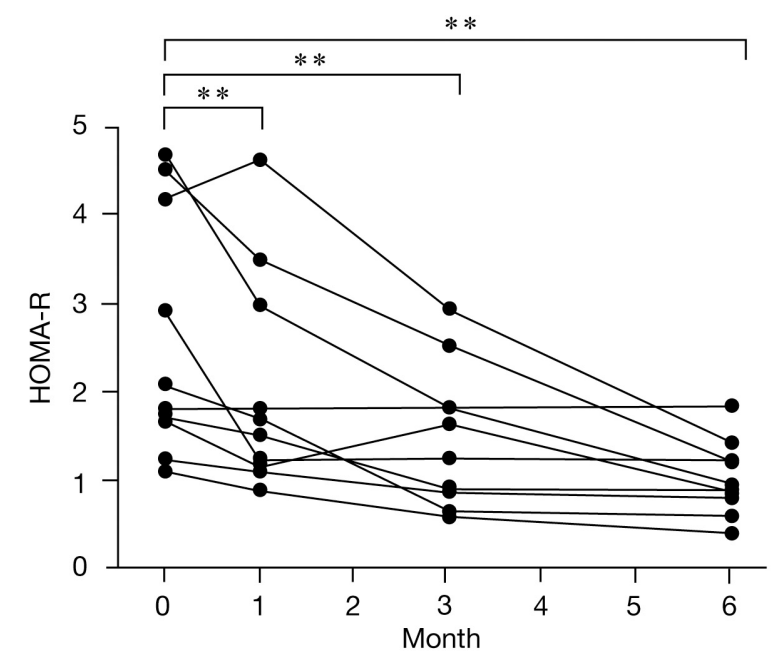

Fig. 1 Serial changes in HOMA-R in patients with Graves' disease during MMI therapy $(\mathrm{n}=10) . * * P<0.01$

\section{Serum IL-18 levels in Graves' disease}

At the time of disease diagnosis in the study group, the mean serum IL-18 level was $334.9 \pm 82.0 \mathrm{pg} / \mathrm{mL}$; it decreased significantly during treatment with anti-thyroid drugs ( 1 month, $311.3 \pm 90.1 \mathrm{pg} / \mathrm{mL} ; 3$ months, $288.9 \pm 81.5 \mathrm{pg} / \mathrm{mL} ; 6$ months, $210.1 \pm 56.9 \mathrm{pg} / \mathrm{mL}$; Fig. 2).

\section{Correlation between IL-18 levels and thyroid hormone levels in Graves' disease}

At all the time points of examination in this study, a significant positive correlation was observed between serum IL-18 levels and the fT3 level in Graves' disease (Fig. 3a). A significant positive correlation was also observed between serum IL-18 levels and the fT4 level (Fig. 3b).

\section{Correlation between IL-18 levels and HOMA-R in Graves'disease}

In the patients with Graves' disease, a significant positive correlation was observed between serum IL-18 levels and HOMA-R at all time points of examination (Fig. 3c).

\section{Serum IL-18 levels in T4-treated mice}

Compared with control mice, the T4-treated mice showed a significantly higher serum IL-18 level(Fig.4a).

\section{Insulin resistance in T4-treated mice}

We performed IPGTT in T4-treated and control mice. Serum IRI levels were higher in the T4-treated

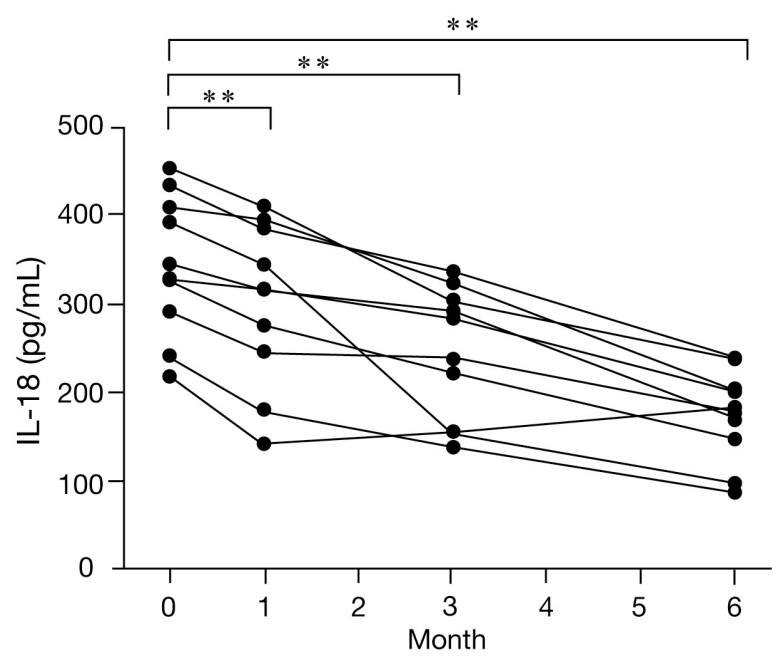

Fig. 2 Serial changes in serum IL-18 levels in patients with Graves' disease during MMI therapy $(\mathrm{n}=10) . * * P<0.01$

mice than in the control mice (Fig. 4b). Plasma glucose levels were also higher in the T4-treated mice than in the control mice (Fig. 4c). On IPGTT, the areas under the curve (AUC) for PG and IRI were significantly greater in the T4-treated mice than in the control mice (Fig. 4d).

\section{Insulin resistance in IL-18-treated mice}

We performed the IPGTT to examine effects on insulin resistance of IL-18 in vivo. The PG and IRI levels in the IL-18-treated mice were significantly higher than those in the control mice (Fig. 5a, b). On IPGTT, the AUC for PG and IRI were significantly greater in the IL-18-treated mice than in the control mice (Fig. 5c). The body weight, liver weight, pancreas weight, and epididymal fat weight of the IL-18-treated mice were the same before and after the injection period.

\section{Discussion}

We first examined the relationship between thyroid hormones and insulin resistance to investigate whether interleukin-18 (IL-18) contributes to increased insulin resistance in hyperthyroidism. Glucose concentrations tended to be well above normal after oral glucose administration to patients with thyrotoxicosis. Glucose intolerance has been reported in up to $57 \%$ of patients with thyrotoxicosis [14]. In this study, we confirmed that HOMA-R rises in patients with hyperthyroid Graves' disease. However, HOMA- $\beta$ indicated that insulin secretion did not decrease in these patients. 

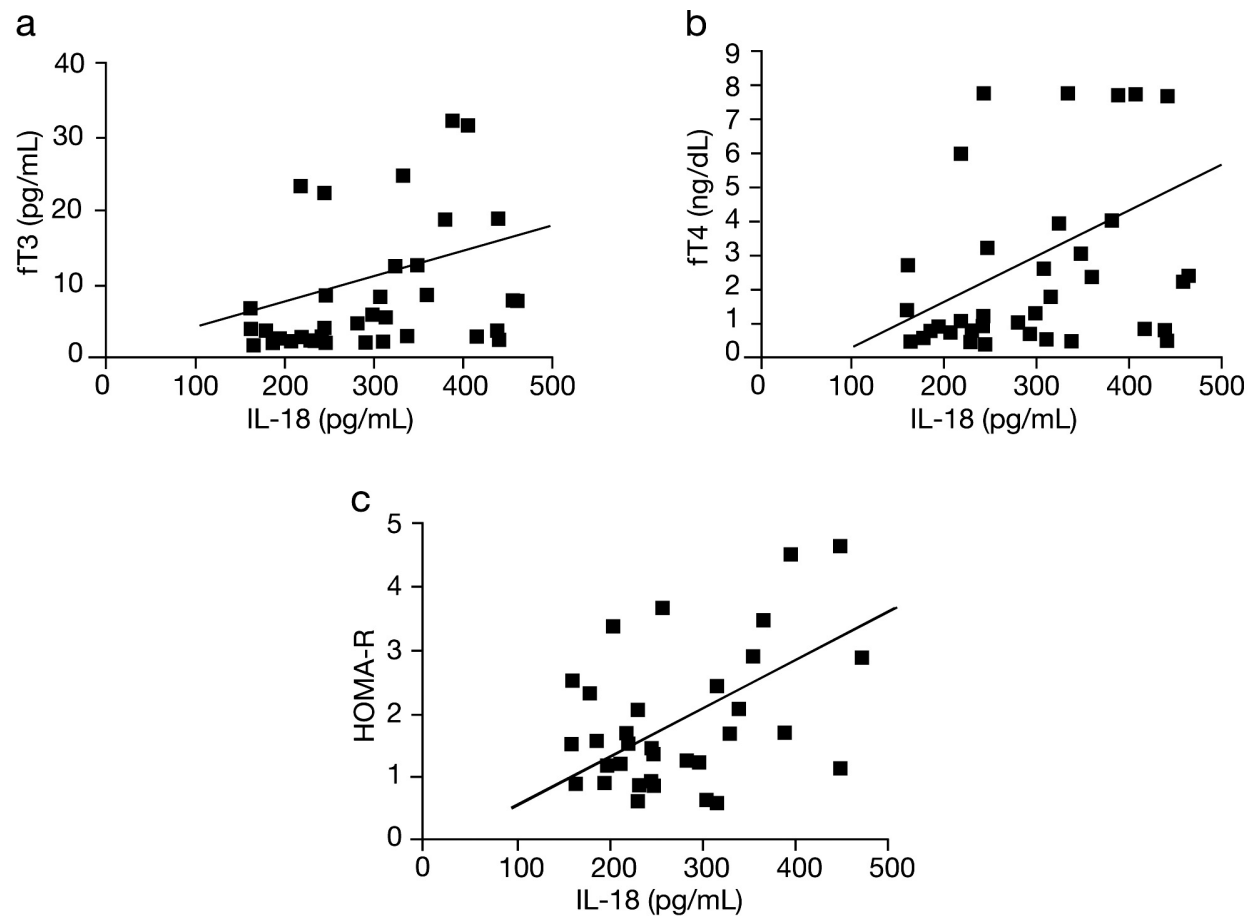

Fig. 3 (a) Correlation between serum IL-18 and free T3 (fT3) levels in patients with Graves' disease ( $\mathrm{n}=40)$. $\mathrm{R}=0.437, P<0.01$

(b) Correlation between serum IL-18 and free T4 (fT4) levels in patients with Graves' disease (n=40). $\mathrm{R}=0.302, P<0.05$

(c) Correlation between serum IL-18 and HOMA-R levels in patients with Graves' disease $(\mathrm{n}=40)$. $\mathrm{R}=0.289, P<0.05$
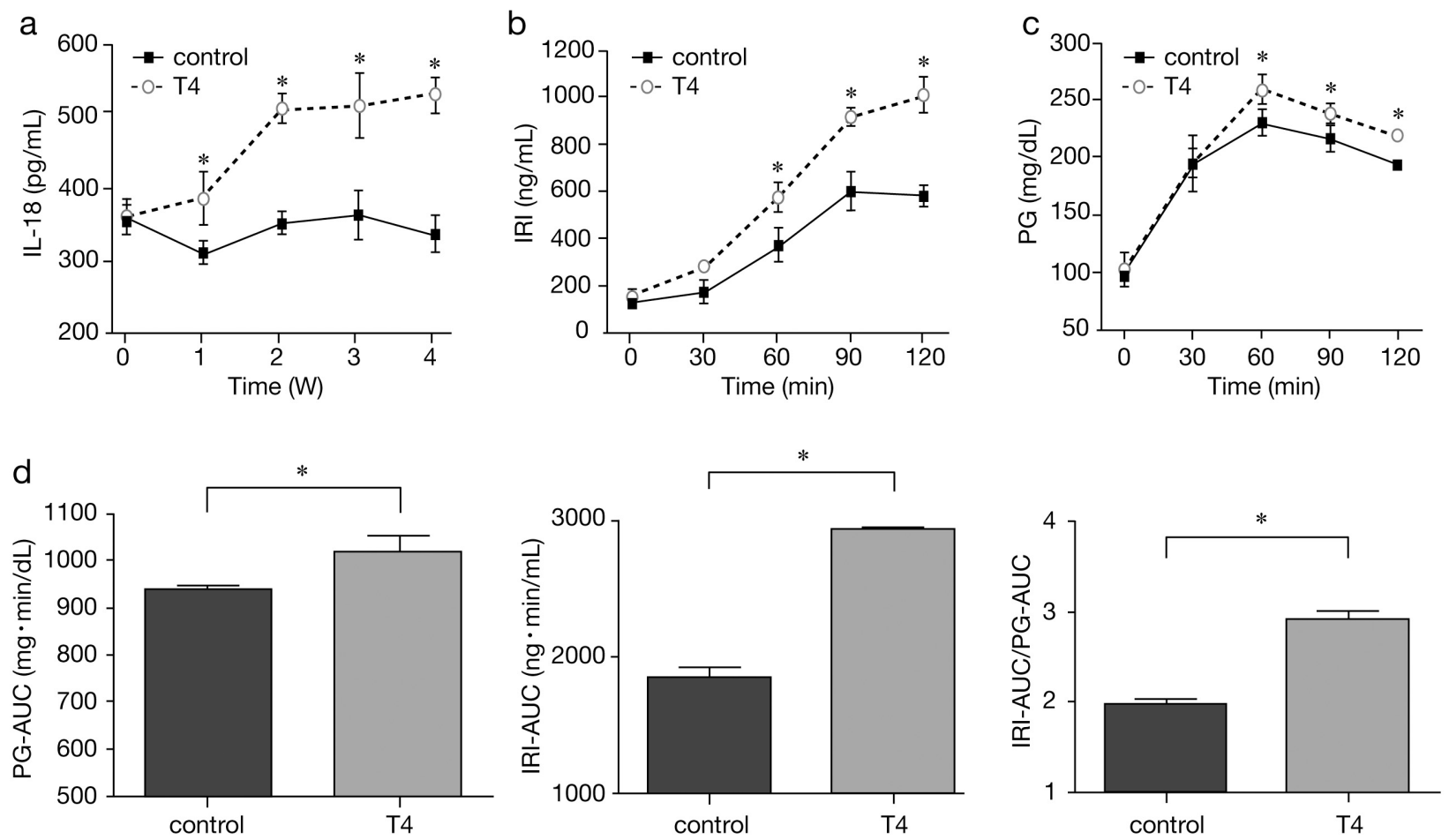

Fig. 4 (a) Changes in serum IL-18 levels in mice administered T4 for 4 weeks $(n=5)$.

(b) Effects on blood IRI levels in T4-treated mice by IPGTT $(n=5)$.

(c) Effects of T4 treatment on PG levels in mice, analyzed by the IPGTT $(n=5)$.

(d) The areas under the curve (AUC) of glucose and insulin during IPGTT in T4-treated mice $(\mathrm{n}=5) . * P<0.05$ 
a

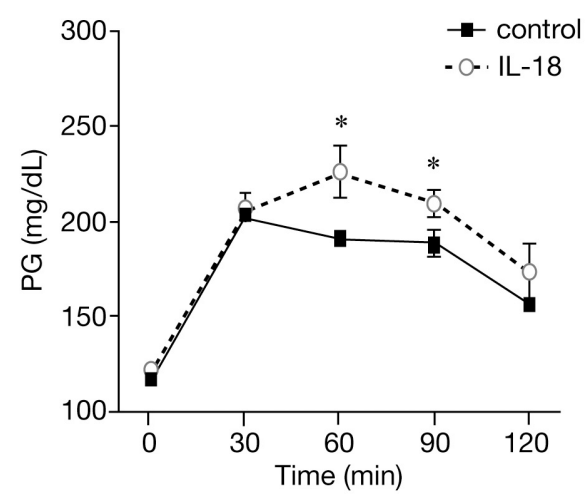

b

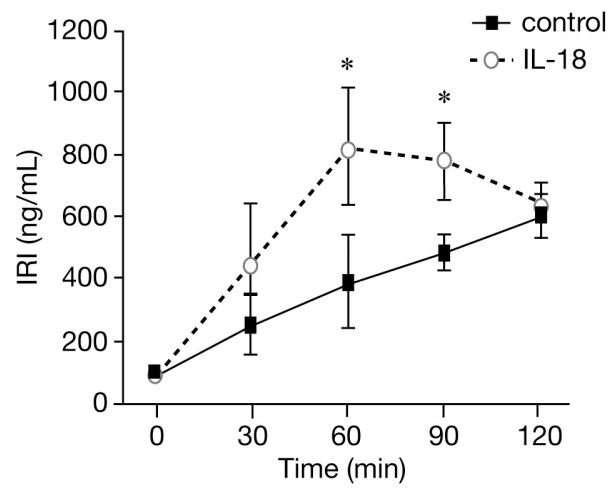

C
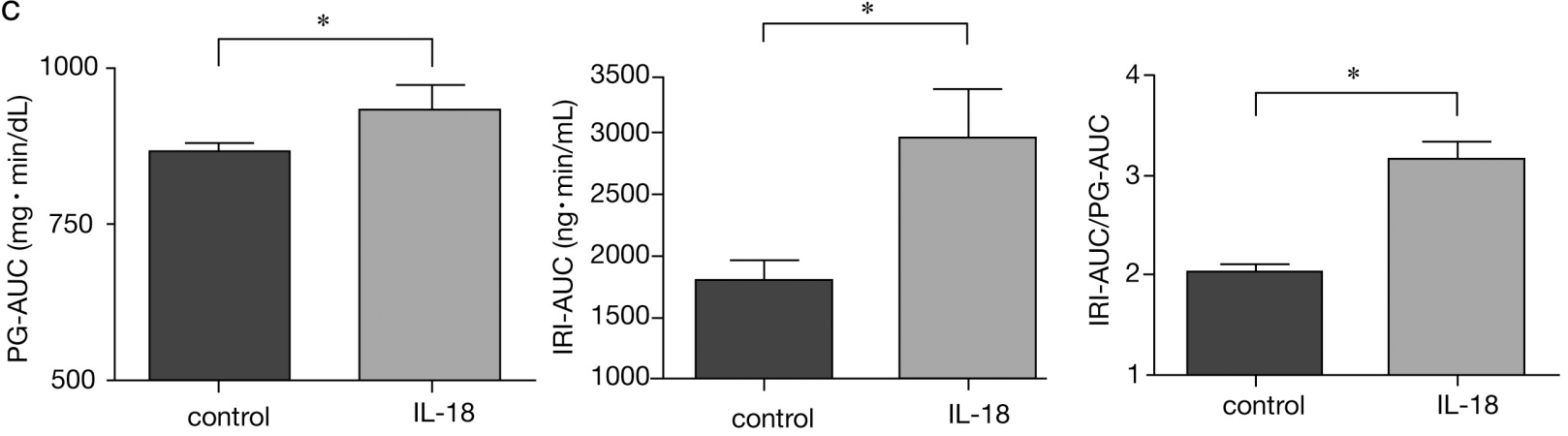

Fig. 5 (a)Effects of IL-18 treatment on PG levels in mice, analyzed by the IPGTT ( $\mathrm{n}=5)$.

(b)Effects on IRI levels in IL-18-treated mice by IPGTT $(n=5)$.

(c)The areas under the curve (AUC) of glucose and insulin in IL-18-treated mice during IPGTT ( $\mathrm{n}=5)$. ${ }^{*} P<0.05$

HOMA-R in patients with hyperthyroid Graves' disease decreased as thyroid function improved. Therefore, we speculate that thyrotoxicosis exacerbates insulin resistance in patients with hyperthyroid Graves' disease.

IL-18 is a member of the IL-1 family of cytokines and is reportedly an interferon gamma (IFN- $\gamma$ ) inducing factor [15]. IL-18 is produced in many different cell types, including macrophages, endothelial cells, vascular smooth muscle cells, dendritic cells and Kupffer cells [16-18]. Recently, several studies have shown IL-18 to be associated with insulin resistance [19-21]. In a large cross sectional study, IL-18 elevations were associated with increasing insulin resistance even after adjustment for obesity, IL6 and C-reactive protein [22]. IL-18 is also elevated in subjects with metabolic syndrome [9]. Serum levels of IL-18 have consistently been reported to be elevated in patients with type 2 diabetes mellitus [20, 23, 24]. Previously, we reported the levels of several cytokines such as IL-12 and IL-18 to be increased in hyperthyroid Graves' disease [8, 25]. A previous study reported that serum levels of IL-18 increase in patients with Graves' ophthalmopathy [26]; however, this finding remains controversial [27].

It is widely reported that IL-6 and tumor necrosis factor alfa (TNF $\alpha)$ are related to the development of insulin resistance in hyperthyroidism [28]. The roles of these 2 cytokines are important in the pathogenesis of insulin resistance. On the other hand, the role of IL-18 in the development of insulin resistance in hyperthyroidism is unclear. Because the IL-18 elevations were suggested to contribute to the pathogenesis of insulin resistance in hyperthyroidism, we next analyzed the relationship between IL-18 and insulin resistance in patients with Graves' disease. The IL-18 levels in our patients with Graves' disease were high before starting treatment, and then decreased as thyroid functions improved during MMI therapy. IL-18 levels correlated positively with fT 3 and fT4 in patients with Graves' disease. Moreover, a significant correlation was observed between IL-18 levels and HOMA-R. These results suggest that hyperthyroidism contributes to the development of insulin resistance through increased IL-18 levels in patients with Graves' disease.

We next examined the relationship between serum 
IL-18 and thyroid hormone levels in mice. IL-18 levels in hyperthyroid mice were significantly increased as compared with those in control mice. IRI levels in hyperthyroid mice were also significantly elevated as compared with those in control mice on IPGTT. The PG levels in hyperthyroid mice were, like those of IRI, significantly higher than those in control mice. On IPGTT, the AUC of PG and IRI were significantly increased in T4-treated mice, reflecting impairment in insulin sensitivity (Fig. 4d). Data obtained from fasting T4-treated mice were not significantly different; however, HOMA-R measured in fasting Graves' patients was significantly different. The reason for this difference may be the short T4 treatment in mice. These results suggest that hyperthyroidism contributes to the development of insulin resistance in this murine model.

To determine whether IL-18 induces insulin resistance, we analyzed the levels of IRI and PG by IPGTT in mice injected with IL-18 for 1 week. The IRI and PG levels in IL-18-treated mice were significantly higher than those in control mice. Moreover, on IPGTT, AUC of PG and IRI were significantly higher in the IL-18treated mice, reflecting impairment in insulin sensitivity (Fig. 5c). These results indicate that IL-18 directly induces insulin resistance in mice. To the best of our knowledge, this is the first study to demonstrate that IL-18 directly induces insulin resistance.

Furthermore, to determine whether hyperthyroidism affects insulin resistance via IL-18, the evaluation of IL-18 levels in knockout mice in a hyperthyroid state or the effect of the neutralizing antibody for insulin resistance is necessary. However, these experiments have not been performed.

So-called inflammasomes were recently implicated in the induction of caspase-I activation and subsequent IL-1 $\beta$ and IL-18 secretions [29]. Reduced IL-1 $\beta$ and NLRP3 expressions were coupled with less severe hyperglycemia and an improvement in HOMA-R. IL-18 may increase insulin resistance via the inflammsome/caspase-I pathway.

In conclusion, our results demonstrate that increased serum IL-18 levels contribute to the development of insulin resistance in hyperthyroidism.

\section{Disclosure Statement}

The authors declare that there are no competing financial interests.

\section{References}

1. Maxon HR, Kreines KW, Goldsmith RE, Knowles HC, Jr. (1975) Long-term observations of glucose tolerance in thyrotoxic patients. Arch Intern Med 135: 14771480.

2. Sandler MP, Robinson RP, Rabin D, Lacy WW, Abumrad NN (1983) The effect of thyroid hormones on gluconeogenesis and forearm metabolism in man. $J$ Clin Endocrinol Metab 56: 479-485.

3. Bratusch-Marrain PR, Komjati M, Waldhausl WK (1985) Glucose metabolism in noninsulin-dependent diabetic patients with experimental hyperthyroidism. $J$ Clin Endocrinol Metab 60: 1063-1068.

4. Randin JP, Tappy L, Scazziga B, Jequier E, Felber JP (1986) Insulin sensitivity and exogenous insulin clearance in Graves' disease. Measurement by the glucose clamp technique and continuous indirect calorimetry. Diabetes 35: 178-181.

5. Shen DC, Davidson MB, Kuo SW, Sheu WH (1988) Peripheral and hepatic insulin antagonism in hyperthyroidism. J Clin Endocrinol Metab 66: 565-569.

6. Foss MC, Paccola GM, Saad MJ, Pimenta WP, Piccinato CE, et al. (1990) Peripheral glucose metabolism in human hyperthyroidism. J Clin Endocrinol Metab 70: 1167-1172.
7. Okamura H, Nagata K, Komatsu T, Tanimoto T, Nukata Y, et al. (1995) A novel costimulatory factor for gamma interferon induction found in the livers of mice causes endotoxic shock. Infect Immun 63: 3966-3972.

8. Miyauchi S, Matsuura B, Onji M (2000) Increased levels of serum interleukin-18 in Graves' disease. Thyroid 10: $815-819$.

9. Van Guilder GP, Hoetzer GL, Greiner JJ, Stauffer BL, Desouza CA (2006) Influence of metabolic syndrome on biomarkers of oxidative stress and inflammation in obese adults. Obesity (Silver Spring) 14: 2127-2131.

10. Matthews DR, Hosker JP, Rudenski AS, Naylor BA, Treacher DF, et al. (1985) Homeostasis model assessment: insulin resistance and beta-cell function from fasting plasma glucose and insulin concentrations in man. Diabetologia 28: 412-419.

11. Turner RC, Holman RR, Matthews D, Hockaday TD, Peto J (1979) Insulin deficiency and insulin resistance interaction in diabetes: estimation of their relative contribution by feedback analysis from basal plasma insulin and glucose concentrations. Metabolism 28: 10861096.

12. Davies TF, Weiss I, Gerber MA (1984) Influence of methimazole on murine thyroiditis. Evidence for immu- 
nosuppression in vivo. J Clin Invest 73: 397-404.

13. Andrikopoulos S, Blair AR, Deluca N, Fam BC, Proietto $\mathrm{J}$ (2008) Evaluating the glucose tolerance test in mice. Am J Physiol Endocrinol Metab 295: E1323-1332.

14. Kreines K, Jett M, Knowles HC Jr. (1965) Observations in hyperthyroidism of abnormal glucose tolerance and other traits related to diabetes mellitus. Diabetes 14: 740-744.

15. Okamura H, Tsutsi H, Komatsu T, Yutsudo M, Hakura A, et al. (1995) Cloning of a new cytokine that induces IFN-gamma production by T cells. Nature 378: 88-91.

16. Dinarello CA (2007) Interleukin-18 and the pathogenesis of inflammatory diseases. Semin Nephrol 27: 98-114.

17. Gerdes N, Sukhova GK, Libby P, Reynolds RS, Young JL, et al. (2002) Expression of interleukin (IL)-18 and functional IL-18 receptor on human vascular endothelial cells, smooth muscle cells, and macrophages: implications for atherogenesis. J Exp Med 195: 245-257.

18. Dinarello CA (2002) The IL-1 family and inflammatory diseases. Clin Exp Rheumatol 20 (5 Suppl 27): S1-13.

19. Straczkowski M, Kowalska I, Nikolajuk A, Otziomek E, Adamska A, et al. (2007) Increased serum interleukin-18 concentration is associated with hypoadiponectinemia in obesity, independently of insulin resistance. Int J Obes (Lond) 31: 221-225.

20. Fischer CP, Perstrup LB, Berntsen A, Eskildsen P, Pedersen BK (2005) Elevated plasma interleukin-18 is a marker of insulin-resistance in type 2 diabetic and nondiabetic humans. Clin Immunol 117: 152-160.

21. Bosch M, Lopez-Bermejo A, Vendrell J, Musri M, Ricart W, et al. (2005) Circulating IL-18 concentration is associated with insulin sensitivity and glucose tolerance through increased fat-free mass. Diabetologia 48:
1841-1843.

22. Hung J, McQuillan BM, Chapman CM, Thompson PL, Beilby JP (2005) Elevated interleukin-18 levels are associated with the metabolic syndrome independent of obesity and insulin resistance. Arterioscler Thromb Vasc Biol 25: 1268-1273.

23. Esposito K, Nappo F, Giugliano F, Di Palo C, Ciotola M, et al. (2003) Cytokine milieu tends toward inflammation in type 2 diabetes. Diabetes Care 26: 1647.

24. Aso Y, Okumura K, Takebayashi K, Wakabayashi S, Inukai T (2003) Relationships of plasma interleukin-18 concentrations to hyperhomocysteinemia and carotid intimal-media wall thickness in patients with type 2 diabetes. Diabetes Care 26: 2622-2627.

25. Tamaru M, Matsuura B, Onji M (1999) Increased levels of serum interleukin-12 in Graves' disease. Eur $J$ Endocrinol 141: 111-116.

26. Mysliwiec J, Kretowski A, Stepien A, Mironczuk K, Kinalska I (2003) Interleukin 18 and transforming growth factor beta1 in the serum of patients with Graves' ophthalmopathy treated with corticosteroids. Int Immunopharmacol 3: 549-552.

27. Wakelkamp IM, Prummel MF, Wiersinga WM (2004) Serum IL-18 levels are not increased in patients with untreated Graves' ophthalmopathy. Horm Metab Res 36: 44-47.

28. Mitrou P, Boutati E, Lambadiari V, Tsegka A, Raptis AE, et al. (2010) Insulin resistance in hyperthyroidism: the role of IL6 and TNF alpha. Eur J Endocrinol 162: 121-126.

29. Wen H, Gris D, Lei Y, Jha S, Zhang L, et al. (2011) Fatty acid-induced NLRP3-ASC inflammasome activation interferes with insulin signaling. Nat Immunol 12: 408-415. 